\title{
Trends in US newspaper and television coverage of tobacco
}

\author{
David E Nelson, ${ }^{1}$ Linda L Pederson, ${ }^{2}$ Paul Mowery, ${ }^{3}$ Sarah Bailey, ${ }^{4}$ \\ Varadan Sevilimedu, ${ }^{3}$ Joel London, ${ }^{4}$ Stephen Babb, ${ }^{4}$ Terry Pechacek ${ }^{4}$
}

${ }^{1}$ Cancer Prevention Fellowship Program, Division of Cancer Prevention, National Cancer Institute, Bethesda, Maryland, USA

${ }^{2}$ McKing Consulting

Corporation, Atlanta, Georgia, USA

${ }^{3}$ Biostatistics, Inc., Atlanta, Georgia, USA

${ }^{4}$ Office on Smoking and Health, National Center for Chronic Disease and Health Promotion, Centers for Disease Control and Prevention, Atlanta, Georgia, USA

Correspondence to Dr David E Nelson, 9609 Medical Center Drive, Suite 2W-138, MSC 9712,

Bethesda, MD 20892-9712,

USA; nelsonde@mail.nih.gov

Received 10 January 2013 Revised 6 June 2013 Accepted 23 June 2013 Published Online First 17 July 2013
CrossMark

To cite: Nelson $\mathrm{DE}$, Pederson LL, Mowery $P$, et al. Tob Control 2015;24:94-99.

\section{ABSTRACT}

Purpose The news media plays an important role in agenda setting and framing of stories about tobacco control. The purpose of this study was to examine newspaper, newswire and television coverage of tobacco issues in the USA over a 7-year period.

Methods Analyses of 2004-2010 news media surveillance system data from the US Centers for Disease Control and Prevention's Office on Smoking and Health, based on content analysis and quantitative methods. Information on extent of news coverage, and types of tobacco-related themes, were examined from articles in 10 newspapers and 2 major newswires, as well as transcripts from 6 national television networks.

Results The overall extent of newspaper, newswire and television stories about tobacco, and level of coverage by specific media outlets, varied over time, especially for newspapers. Nevertheless, there was an average of 3 newspaper stories, 4 newswire stories, and 1 television tobacco-related story each day. Television stories were more likely to contain cessation/addiction or health effects/statistics themes and less likely to contain secondhand smoke or policy/regulation themes than newspaper/newswire stories. There was more variation in the choice of tobacco theme among individual newspapers/newswires than television media outlets. Conclusions News coverage of tobacco in the USA was relatively constant from 2004 to 2010 . Audiences were more likely to be exposed to different tobacco themes in newspapers/newswires than on television. Tracking information about tobacco news stories can be used by advocates, programs and others for planning and evaluation, and by researchers for hypothesis generation.

\section{INTRODUCTION}

The news media can reflect and impact attitudes and beliefs of the public and policy makers about public health and other issues. ${ }^{1-3}$ They are particularly influential in agenda setting and framing, that is, what information is considered important and how topics are discussed. ${ }^{1}$ Tobacco control advocates have understood the importance of the news media, and have been successful over the past 25 years in gaining news media coverage. ${ }^{2} 45$ Indeed, media outreach efforts have contributed to adoption of tobacco control and prevention policies and have influenced individual behaviour, leading to reductions in smoking prevalence. ${ }^{4}$ Thus, it is important that tobacco-related issues continue to receive news coverage and maintain media presence.

However, others also desire news media coverage, leading to competition for the limited space (ie, the 'news hole'). Health topics, such as disease outbreaks and obesity, also receive media attention. ${ }^{67}$ Although certain tobacco events have been well covered recently, such as the US Food and Drug Administration (FDA) regulation of tobacco, tobacco may be considered 'solved' or 'old news', and not newsworthy. ${ }^{7}$

A description of the national news media surveillance system developed by the US Centers for Disease Control and Prevention's Office of Smoking and Health (CDC/OSH) for monitoring newspaper, newswire and television coverage of tobacco control topics, was published in 2007. ${ }^{9}$ Australia, to our knowledge, is the only other country systematically tracking news media coverage of tobacco (in newspapers) using a surveillance model. ${ }^{5} 710$ The CDC/OSH system was designed to regularly collect limited data from selected sources to monitor the coverage and mix of tobacco-related themes in news stories in newspapers, newswires and on television; identify emerging tobacco topics; help assess the impact of media outreach and tobacco control efforts; and guide programme activities. ${ }^{9}$ A strength of this system is the inclusion of television transcript data about tobacco stories, as most tobacco media studies rely on print media. Television has a greater reach than print media outlets, ${ }^{11}$ which means more people are likely to be exposed to tobacco stories appearing in this medium.

Major findings from the previous study, which covered January 2004 to June 2005, were that tobacco stories appeared in newspapers or newswires on an almost daily basis, but there was variability in coverage and themes, especially for newspapers compared with television. ${ }^{9}$ Policy/regulation, legal/lawsuits, or health effects/statistics themes were present in more than $70 \%$ of all newspaper/newswire or television stories.

There have been several studies on tobacco news coverage ${ }^{4}$ but few have examined changes over time. Stillman et al examined media advocacy effects on newspaper coverage in selected US states from 1994 to $1998 .{ }^{12}$ They found variability in the yearly rate of tobacco news stories, and for stories containing youth access, advertising and promotion, clean indoor air and economic disincentive themes. Clean indoor stories declined by more than threefold after 1994. Similarly, Wakefield et $a l^{7}{ }^{7}$ in a study of tobacco news stories from 12 Australian newspapers from 2001 to 2006, also found year-to-year variability in the volume of tobacco stories without evidence for an overall decline. They reported statistically significant increases in the proportion of articles on secondhand smoke; 
decreases for prevention, cessation and education; and no change for health effects.

The purpose of this study is to update and extend prior research of news media coverage of tobacco in the USA for 2004-2010. Specific research questions were: (1) What was the extent of coverage of tobacco stories by newspapers/newswire services and television networks; were there differences between them; and did they change over time? (2) What were the major themes used by newspapers/newswire services and television networks in tobacco stories; were there differences between them; and did they change over time? (3) What was the prominence of tobacco themes-based newspaper headlines or placement early within television news transcripts (2007-2010 only)?

\section{METHODS}

Data were obtained from the US CDC's Office on Smoking and Health (OSH) tobacco news media surveillance system from 2004 to 2010; details are available elsewhere. ${ }^{9}$ Briefly, coders identified and coded tobacco-related newspaper, newswire and television stories. The choice of news outlets was based on circulation size, geographic diversity and prominence. ${ }^{9}$ Ten newspapers were coded across all years: Atlanta JournalConstitution, Boston Globe, Chicago Tribune, Dallas Morning News, Los Angeles Times, New York Times, San Francisco Chronicle, USA Today, Wall Street Journal and Washington Post. Newswire stories were coded from Reuters and the Associated Press; television transcripts from national broadcast and cable television networks (ABC, NBC, CBS, Fox Network, Fox News Channel, $\mathrm{CNN}$ and MSNBC).

Daily searches for tobacco stories were conducted using online news databases, including LexisNexis (San Francisco) and Video Monitoring Service (New York). Search terms included: cigarette, cigar, clean indoor air, nicotine, secondhand smoke, smoker, smoking and tobacco.

Detailed codebooks were developed by OSH, and coders trained to identify and code relevant articles and transcripts. Stories and editorials containing more than a passing reference to tobacco, smoking, or tobacco control issues were included, with letters to the editor excluded.

Variables identified for coding were based on previous media research and OSH programme interests. ${ }^{9} 13$ Variables included information on media outlets and the extent of media coverage, population groups (eg, youth, race/ethnicity group), and specific tobacco themes. ${ }^{\text {i }}$ Tobacco themes were coded using a two-part process. First, articles and television transcripts were initially reviewed to identify whether they contained a cessation/addiction, secondhand smoke, or initiation/prevention theme (Main Theme I). These themes were selected because they are major areas of emphasis for CDC/OSH. Second, articles and transcripts were re-reviewed and coded to identify other tobacco themes (Main Theme II), namely, policy/regulation, health effects/statistics, legal/lawsuits, taxes/price of products, and economics/business. Coding of prominence for specific tobacco-related information in newspapers and newswire service article headlines, and for television transcript lead-in text (within the first 200 words), began in 2007.

Ongoing reliability testing for selected variables was conducted using a 10\% random sample of newspaper, newswire and television stories by two independent coders. Mean item-

${ }^{\mathrm{i}}$ Note: more than one main tobacco theme could be coded per news article or television transcript. specific kappa values were $0.76-0.79$ for newspaper/newswire items, and 0.72-0.74 for television transcript items.

Yearly datasets were cleaned to eliminate duplicate stories or stories where tobacco was not the major focus (1922 newspaper/newswire articles and 1067 television transcripts were eliminated). Newspaper and newswire article datasets, and television transcript datasets, were merged to contain only variables coded from 2004 to 2010. Statistical analyses were performed using SAS (Cary, North Carolina) V.9.2.

For pooled analyses, newspaper and newswire data were combined because analyses conducted separately revealed similar findings. Data from Fox Network and Fox News Channel television transcripts were combined and coded as Fox News. Separate analyses across all years were conducted for newspapers/newswires and television transcripts.

Potential differences in distributions over time, and by specific tobacco themes, among news media outlets were assessed using $\mathrm{p}$ values from $\chi^{2}$ tests. To assess potential linear trends in the proportion of stories by specific themes, we developed scatter plots and conducted linear regression modelling. Goodnessof-fit was based on adjusted $\mathrm{R}^{2}$, with $>0.50$ used as the cutpoint. Of the 16 models tested, only five met this linear fit criterion. Because preliminary analyses revealed differences in tobacco themes in newspapers/newswires compared with television, logistic regression was conducted to formally assess differences between them from 2004 to 2010, controlling for time period (in quarters). Differences were expressed as ORs with 95\% CIs using newspapers/newswires as the baseline. Analyses were conducted from 2007 to 2010 on prominence of tobacco themes based on presence in newspaper/newswire headlines or in the first 200 words of television transcripts.

\section{RESULTS}

There were 7402 newspaper, 10236 newswire and 2319 television tobacco stories from 2004 to 2010 . There was year-to-year variability in coverage of tobacco stories for selected newspapers (figure 1A; $\mathrm{p}<0.0001$ ). However, the New York Times and Chicago Tribune generally had a higher, and the Dallas Morning News and San Francisco Chronicle generally had a lower, percentage of tobacco-related stories. Most newswire stories across all years (79.5-87.7\%) were from the Associated Press. There was also year-to-year variability in tobacco coverage by individual television network $(p<0.0001)$. However, except for 2006, $\mathrm{CNN}$ was much more likely to carry tobacco stories than other networks, accounting for nearly half the television stories in all years (figure $1 \mathrm{~B}$ ).

The overall combined number of newspaper and newswire stories per month fluctuated widely (figure 2A). The mean number of newspaper/newswire stories per month was 218 (SD 105.6, range 26-478), amounting to, on average, about seven newspaper/newswire tobacco stories per day (an average of three in newspapers and four on newswires). Several large spikes were seen, such as during October 2007, May 2008 and June 2009, when the FDA Family Smoking Prevention and Tobacco Control Act was considered by Congress. Television coverage of tobacco was much less common than for newspaper/newswire services (figure 2B), with a monthly mean of 29 stories (SD 19.0, range: 3-79), or, on average, about one television story per day. There were several notable spikes in television coverage, only some of which were similar to those occurring for newspapers/newswires on the same topics.

Specific populations (ie, age or race/ethnicity) were rarely a focus, mentioned in only $16 \%$ of newspaper/newswire and $26 \%$ of television tobacco stories; when mentioned, youth was the 


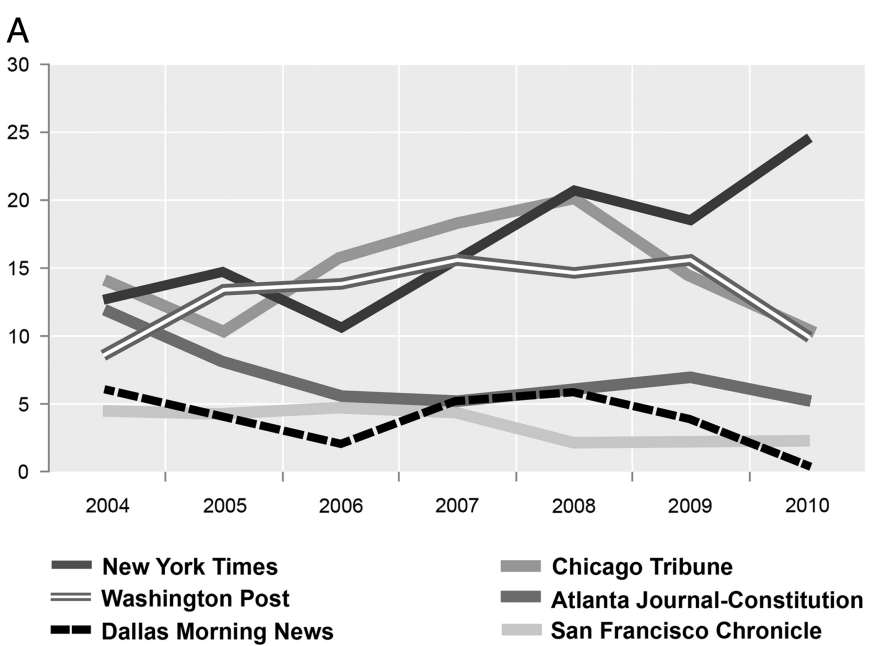

B

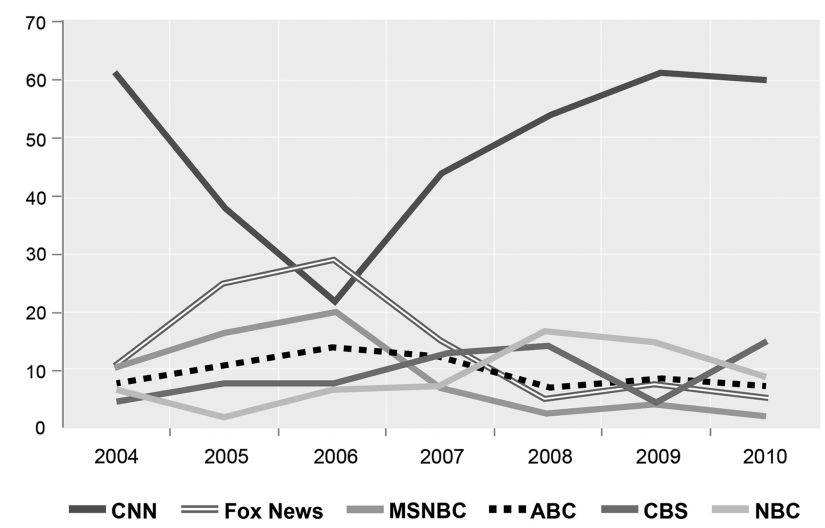

Figure 1 (A) Three newspapers with the highest and lowest percentage of tobacco stories across all years, 2004-2010. (B) Percent of tobacco stories by television network and year, 2004-2010.

population group most often named (data not shown in tables). A tobacco-related phrase was mentioned in the headlines of newspaper/wire service tobacco stories from $55 \%$ to $85 \%$ of the time from 2007 to 2010 (data not shown in tables). Mention in the first 200 words of a television transcript occurred for 20 $40 \%$ of stories prior to the passage of the FDA bill in 2009; afterward, it was $53-80 \%$.

Both Main Theme I (cessation/addiction, secondhand smoke, or initiation/prevention) and Main Theme II (policy/regulation, health effects/statistics, taxes/prices of products, tobacco economic/business, legal/lawsuits) varied yearly in newspapers/newswire and television stories (table 1). There were differences among the newswire services in terms of themes. For example for Main Theme I, $41 \%$ of Associated Press contained a secondhand smoke theme compared with $18 \%$ for Reuters, whereas for Main Theme II, $18 \%$ of Reuters stories concerned economics or business compared with 6\% for the Associated Press ( $\mathrm{p}<0.001$ for both comparisons; data not shown in tables). Linear models found for newspapers/newswires, the percentage of stories with an initiation/prevention theme declined by an average of 1.6 percentage points per year $\left(95 \% \mathrm{CI}:-2.6\right.$ to $-0.6 ; \mathrm{R}^{2}=0.73$ ), whereas stories with taxes/price of product theme increased by an average of 1.7 percentage points annually ( $95 \%$ CI 0.9 to 2.5 ; $\mathrm{R}^{2}=0.82$ ). For television, linear models showed a 2.2 annual percentage point decrease each year for stories with a legal/lawsuits theme $\left(95 \% \mathrm{CI}-3.2\right.$ to $\left.-1.3 ; \mathrm{R}^{2}=0.89\right)$; a 0.8 percentage point increase annually $\left(95 \% \mathrm{CI} 0.2\right.$ to $\left.1.3 ; \mathrm{R}^{2}=0.64\right)$ for broadcasts with a taxes/price of product theme, and a 1.0 percentage point increase per year $\left(95 \%\right.$ CI 0.1 to $\left.1.8 ; \mathrm{R}^{2}=0.58\right)$ for stories on tobacco economics/business.

In all years, newspapers/newswires were more likely to carry stories emphasising secondhand smoke or policy/regulation than television networks (table 1). By contrast, television stories were more likely to feature cessation/addiction or health effects/statistics themes (table 1). Differences in tobacco themes between newspapers/newswires and television remained in regression analyses. For example, compared with newspapers/newswires, stories with a health effects/statistics theme were much more common on television ( $\mathrm{OR}=4.7,95 \%$ CI 3.8 to 5.7), with themes of policy/ regulation $(\mathrm{OR}=0.4,95 \% \mathrm{CI} 0.3$ to 0.5$)$ and taxes/price of products being less common (OR=0.3, 95\% $\mathrm{CI} 0.2$ to 0.5$)$.

Pooled data across all years revealed much variability in Main Theme I among individual newspapers and newswires (data not shown in tables). Ranges were as follows: $9.2-49.4 \%$ for secondhand smoke; $8.1-18.6 \%$ for cessation/addiction; and $5.4-14.7 \%$ for initiation/prevention. The Wall Street Journal (9.2\%) and Reuters (18.2\%), contained fewer secondhand smoke stories than other newspapers or the Associated Press $(40.7 \%) .{ }^{\text {ii }}$ By contrast, television networks were more similar in the percentage of news stories for Main Theme I (table 2), except that $\mathrm{ABC}, \mathrm{NBC}$ and $\mathrm{CBS}$ were slightly more likely than other networks to include a cessation/addiction theme.

There was also much variability across specific newspapers and newswires in their coverage of certain Main Theme II themes (data not shown in tables), including policy/regulation (range: 7.0-33.1\%), legal/lawsuits (range: 4.5-24.2\%), and economics/business (range: 1.4-21.6\%). The Wall Street Journal (21.6\%) and Reuters (18.2\%) had more stories with economics/ business themes. As with Main Theme I, television networks were fairly similar in their distribution across Main Theme II themes (table 2).

\section{DISCUSSION}

These results extend and expand upon prior US national surveillance research of tobacco news coverage in newspapers, newswires and on television, as there is now a collection of nearly 20000 stories. There were large spikes in the number of tobacco stories in newspapers, ${ }^{7}$ and the level of coverage over time varied. This overall year-to-year variability in tobacco news coverage and themes was also found by Stillman et al ${ }^{12}$ and Wakefield et al. ${ }^{7}$ Nevertheless, from 2004 to 2010, there were approximately three newspaper stories per day on tobacco based on 10 US newspapers. This was similar to findings from 12 Australian newspapers from 2001 to 2006, where there were 6483 tobacco news stories (ie, 2.96 stories per day across all papers). ${ }^{7}$ There were also large spikes in the number of television stories over time, with an average of one tobacco story per day across all networks.

There was much variability among individual news media outlets in their coverage of tobacco across years. Nevertheless, the New York Times and Chicago Tribune were generally more likely, and the Dallas Morning News and San Francisco

ii Note: more detailed tobacco theme data for specific newspapers/ newswires are available from the authors. 
A

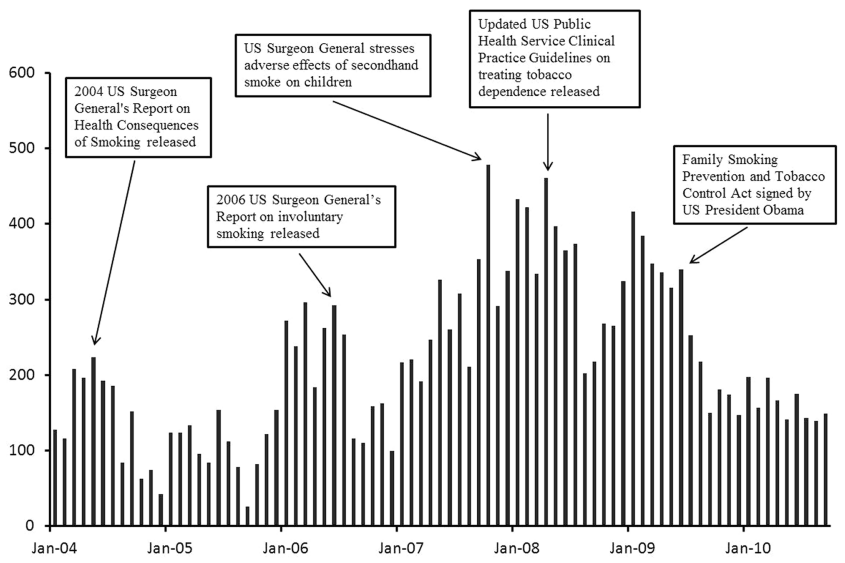

B

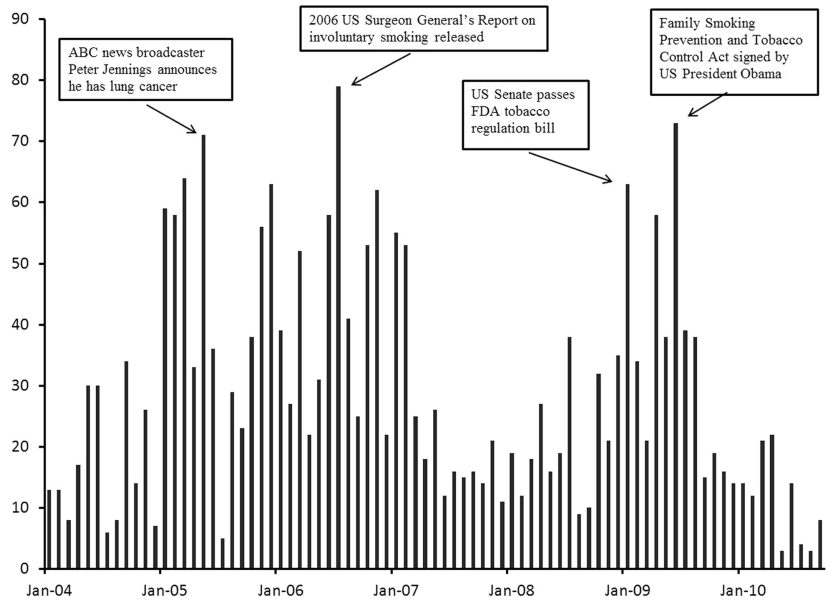

Figure 2 (A) Frequencies of tobacco newspaper/newswire articles published monthly, 2004-2010. (B) Frequencies of television tobacco segments aired monthly, 2004-2010.

Chronicle were less likely, to carry tobacco stories than other newspapers. The Associated Press was responsible for the vast majority of newswire-related tobacco stories and this finding changed little over time. CNN carried slightly less than half of all television tobacco news stories, with the other cable news and broadcast news networks accounting for a much smaller percentage with little variation over time.

Directly comparing tobacco theme frequencies, including trends in the proportion of stories with specific themes, from this study with prior research is difficult because other studies used somewhat different themes and definitions. ${ }^{4} 5712$ 14-18 However, our finding of a linear decline in the proportion of newspaper/newswire tobacco stories with a prevention/initiation theme was similar to the linear decline in education/prevention stories reported by Wakefield et al. ${ }^{7}$ The finding that newspapers/newswires emphasised policy/regulation and secondhand smoke themes, and to a lesser extent, tobacco economics/business and legal/lawsuits themes, was consistent with prior US and Australian studies. ${ }^{4} 9101415$ The limited coverage of tobacco prevention, also reported elsewhere, ${ }^{10}{ }^{15}$ was disappointing; the minimal change in US adolescent tobacco use prevalence over this time might have played a role.

Television tobacco themes differed substantially from those in newspapers, and these differences persisted over time. This is in contrast with the only other study, to our knowledge, that analysed US television tobacco news stories. ${ }^{15}$ Long et al ${ }^{15}$ found no difference for tobacco themes covered in US newspapers compared with television for the years 2002-2003, but their study contained only 21 television news stories. Of note, the most commonly covered television tobacco themes (health effects/statistics and cessation/addiction) tend to be more individual-oriented, while three of the four most common newspaper/newswire themes (policy/regulation, secondhand smoke, and taxes/price of tobacco) tend to be more population-focused and often involve policy. This difference may reflect the tendency of television health stories to more often focus on causes and treatments than newspapers ${ }^{19}$ because they readily lend themselves to visual images (eg, of affected individuals).

Newspaper editors and television producers have an important agenda-setting role, serving as gatekeepers who make decisions about whether a topic or event is 'newsworthy', and thus, reported at all. Measures of the volume of news coverage provides some evidence of differences among individual gatekeepers, for example, producers at $\mathrm{CNN}$ probably consider tobacco stories more newsworthy than producers at other cable news networks. Differences in tobacco themes among individual newspapers and newswire services also strongly suggest that news editors differ in whether and how they choose to report tobacco stories. This result was not surprising, given that news editors and producers have their own worldviews and tend to select or frame stories in ways consistent with their beliefs. ${ }^{20}$ The large difference between tobacco themes in Associated Press compared with Reuters newswire stories, to our knowledge, has not been reported elsewhere for tobacco or other health-related topics. However, Reuters, which is based in the UK and has a global media audience, has a long history of primarily providing financial information, ${ }^{21}$ which may explain why they had a larger percentage of economic/business themes.

By contrast with newspapers/newswires, there were fewer differences in tobacco themes among individual television networks. While this finding has not been reported elsewhere, it is consistent with a large body of research in mass communication demonstrating the general uniformity of reporting (ie, selection of topics deemed newsworthy, framing of stories) among individual television news media outlets for many topics. ${ }^{22}$

This study has limitations. Only selected US newspapers and television networks were tracked over time, and local television news stories were not monitored. US newspaper circulation, in general, is declining, and this decline was substantial for some newspapers (eg, $40 \%$ for the San Francisco Chronicle) since $2008 .{ }^{23}$ No estimates were available for population exposure to internet-only news outlets. Searching and coding were restricted to tobacco-related stories (numerators) and not done for all news stories or health news stories (denominators). This means tobacco stories likely represent only a very small percentage of news stories. Previous research, for example, has shown that the vast majority of health-related news stories emphasise healthcare topics, such as medical treatment or healthcare systems, rather than behaviours such as tobacco use. ${ }^{24}$ Themes for $21 \%$ of newspaper/newswire and $20 \%$ of television stories were coded as 'none of these' for both Main Theme I and Main Theme II, and the impact of this on our results is not known. There was only limited data on prominence of tobacco stories. Finally, data were not available to conduct more in-depth theme analyses, such as the valence of tobacco stories (ie, whether they were protobacco or antitobacco). 
Table 1 Percentages and standard errors for main tobacco themes by news media type, 2004-2010*

\begin{tabular}{|c|c|c|c|c|c|c|c|c|}
\hline Media type and theme & 2004 & 2005 & 2006 & 2007 & 2008 & 2009 & 2010 & All years \\
\hline \multicolumn{9}{|l|}{ Newspapers/newswires } \\
\hline \multicolumn{9}{|l|}{ Main Theme I } \\
\hline Secondhand smoke & $29.6(1.1)$ & $19.7(1.1)$ & $41.9(1.0)$ & $36.3(0.8)$ & $37.0(0.8)$ & $34.8(0.8)$ & $26.4(1.2)$ & $34.3(0.4)$ \\
\hline Cessation/addiction & $19.3(1.0)$ & $12.3(0.9)$ & $7.3(0.5)$ & $7.2(0.4)$ & $14.2(0.6)$ & $12.1(0.6)$ & $13.6(0.9)$ & $11.8(0.2)$ \\
\hline Initiation/prevention & $11.8(0.8)$ & $10.9(0.9)$ & $7.4(0.5)$ & $4.4(0.4)$ & $7.1(0.4)$ & $2.6(0.3)$ & $4.2(0.5)$ & $6.3(0.2)$ \\
\hline None of theset & $39.4(1.2)$ & $57.1(1.4)$ & $43.4(1.0)$ & $52.1(0.9)$ & $41.7(0.8)$ & $50.6(0.9)$ & $55.9(1.3)$ & $47.7(0.4)$ \\
\hline $\mathrm{p}$ Value: & & & & & & & & $p<0.0001$ \\
\hline \multicolumn{9}{|l|}{ Main Theme II } \\
\hline Policy/regulation & $33.4(1.1)$ & $23.9(1.0)$ & $21.0(0.6)$ & $20.7(0.5)$ & $21.0(0.5)$ & $23.7(0.5)$ & $19.2(0.7)$ & $22.1(0.2)$ \\
\hline Health effects/statistics & $16.7(0.9)$ & $16.0(0.9)$ & $7.6(0.4)$ & $7.4(0.3)$ & $8.0(0.3)$ & $8.0(0.3)$ & $10.0(0.6)$ & $8.9(0.2)$ \\
\hline Taxes/price of products & $2.2(0.4)$ & $5.0(0.5)$ & $4.1(0.3)$ & $10.3(0.4)$ & $7.6(0.3)$ & $11.3(0.4)$ & $12.6(0.6)$ & $8.4(0.2)$ \\
\hline Tobacco economics/business & $9.2(0.7)$ & $7.5(0.6)$ & $6.5(0.4)$ & $6.9(0.3)$ & $9.9(0.3)$ & $6.4(0.3)$ & $8.9(0.5)$ & $7.8(0.2)$ \\
\hline Legal//awsuits & $22.3(1.0)$ & $15.8(0.9)$ & $8.8(0.4)$ & $3.2(0.2)$ & $6.6(0.3)$ & $5.4(0.3)$ & $7.9(0.5)$ & $7.4(0.1)$ \\
\hline None of these $\ddagger \S$ & $16.2(0.9)$ & $31.8(1.1)$ & $52.0(0.7)$ & $51.5(0.6)$ & $47.0(0.6)$ & $45.2(0.6)$ & $41.5(0.9)$ & $45.5(0.3)$ \\
\hline $\mathrm{p}$ Value: & & & & & & & & $p<0.0001$ \\
\hline \multicolumn{9}{|l|}{ Television networks } \\
\hline \multicolumn{9}{|l|}{ Main Theme I } \\
\hline Cessation/addiction & $31.8(3.3)$ & $18.7(1.7)$ & $15.7(1.6)$ & $29.8(2.7)$ & $46.1(3.1)$ & $35.1(2.3)$ & $30.7(4.6)$ & $27.1(0.9)$ \\
\hline Secondhand smoke & $20.9(2.9)$ & $14.8(1.5)$ & $32.3(2.1)$ & $23.8(2.5)$ & $17.2(2.4)$ & $15.2(1.7)$ & $15.8(3.6)$ & $20.7(0.8)$ \\
\hline Initiation/prevention & $23.4(3.0)$ & $9.4(1.3)$ & $8.0(1.2)$ & $2.8(1.0)$ & $6.6(1.6)$ & $3.0(0.8)$ & $5.9(2.4)$ & $7.9(0.6)$ \\
\hline None of theset & $23.9(3.0)$ & $57.2(2.1)$ & $44.0(2.2)$ & $43.6(3.0)$ & $30.1(2.9)$ & $46.7(2.4)$ & $47.5(5.0)$ & $44.4(1.0)$ \\
\hline $\mathrm{p}$ Value: & & & & & & & & $p<0.0001$ \\
\hline \multicolumn{9}{|l|}{ Main Theme II } \\
\hline Health effects/statistics & $70.9(3.2)$ & $29.4(1.7)$ & $16.1(1.2)$ & $16.8(1.6)$ & $26.0(1.9)$ & $18.1(1.3)$ & $22.9(3.0)$ & $23.2(0.7)$ \\
\hline Policy/regulation & $18.0(2.7)$ & $15.9(1.4)$ & $12.8(1.1)$ & $12.8(1.4)$ & $11.1(1.4)$ & $18.7(1.3)$ & $14.4(2.5)$ & $14.7(0.6)$ \\
\hline Legal/lawsuits & $1.5(0.8)$ & $11.7(1.2)$ & $8.8(0.9)$ & $6.0(1.0)$ & $2.3(0.7)$ & $0.9(0.3)$ & $1.5(0.9)$ & $5.7(0.4)$ \\
\hline Taxes/price of products & $1.5(0.8)$ & $2.3(0.6)$ & $1.0(0.3)$ & $3.6(0.8)$ & $2.3(0.7)$ & $4.7(0.7)$ & $6.5(1.7)$ & $2.8(0.3)$ \\
\hline Tobacco economics/business & $0.0(0.0)$ & $2.0(0.5)$ & $1.7(0.4)$ & $0.7(0.4)$ & $5.5(1.0)$ & $2.9(0.6)$ & $7.0(1.8)$ & $2.5(0.3)$ \\
\hline None of these $\ddagger \rrbracket$ & $8.3(1.9)$ & $38.7(1.9)$ & $59.7(1.5)$ & $60.1(2.1)$ & $52.7(2.2)$ & $54.7(1.7)$ & $47.8(3.5)$ & $51.0(0.8)$ \\
\hline $\mathrm{p}$ Value: & & & & & & & & $\mathrm{p}<0.0001$ \\
\hline
\end{tabular}

Despite these limitations, our findings provide important new information and suggest future directions. Gaining and maintaining earned media coverage is an essential strategy in tobacco control and prevention. ${ }^{2}{ }^{4}$ We found that tobacco news coverage in the USA remained stable in recent years, which suggests that efforts by researchers, advocates and others to garner media

Table 2 Percentages and SEs for main tobacco themes by individual television network, all years*

\begin{tabular}{|c|c|c|c|c|c|c|}
\hline & CNN & Fox News & MSNBC & $A B C$ & CBS & NBC \\
\hline \multicolumn{7}{|l|}{ Main Theme I } \\
\hline Cessation/addiction & $28.4(1.4)$ & $20.4(2.0)$ & $17.3(2.4)$ & $32.8(3.0)$ & $30.8(3.3)$ & $36.4(3.5)$ \\
\hline Secondhand smoke & $19.4(1.2)$ & $23.7(2.1)$ & $26.2(2.7)$ & $21.0(2.6)$ & $17.2(2.7)$ & $16.9(2.7)$ \\
\hline Initiation/prevention & $8.4(0.9)$ & $5.3(1.1)$ & $10.8(1.9)$ & $7.6(1.7)$ & $8.1(1.9)$ & $6.7(1.8)$ \\
\hline None of these & $43.9(1.6)$ & $50.6(2.5)$ & $45.8(3.1)$ & $38.7(3.2)$ & $43.9(3.5)$ & $40.0(3.5)$ \\
\hline $\mathrm{p}$ Value: & & & & & & $p<0.0001$ \\
\hline \multicolumn{7}{|l|}{ Main Theme II } \\
\hline Health effects/statistics & $26.8(1.1)$ & $17.5(1.5)$ & $17.9(1.8)$ & $21.6(2.0)$ & $22.5(2.2)$ & $26.4(2.3)$ \\
\hline Policy/regulation & $15.4(0.9)$ & $15.9(1.4)$ & $15.6(1.7)$ & $12.9(1.6)$ & $13.2(1.8)$ & $11.4(1.7)$ \\
\hline Legal/lawsuits & $4.3(0.5)$ & $8.0(1.0)$ & $10.7(1.5)$ & $5.2(1.1)$ & $4.8(1.1)$ & $3.5(1.0)$ \\
\hline Taxes/price of products & $3.3(0.4)$ & $4.2(0.8)$ & $2.2(0.7)$ & $2.1(0.7)$ & $1.4(0.6)$ & $0.6(0.4)$ \\
\hline Tobacco economics/business & $2.5(0.4)$ & $1.3(0.4)$ & $1.3(0.5)$ & $2.8(0.8)$ & $5.1(1.2)$ & $3.5(1.0)$ \\
\hline None of these & $47.7(1.2)$ & $53.0(1.9)$ & $52.2(2.4)$ & $55.5(2.4)$ & $53.0(2.7)$ & $54.4(2.6)$ \\
\hline p Value: & & & & & & $p<0.0001$ \\
\hline
\end{tabular}


attention may have been successful over time. However, it is possible that sustained coverage of tobacco in the USA may have resulted from secular trends of increased health reporting in general, an increased emphasis on policy reporting (eg, smokefree laws), or other factors. Given the importance of the media as an information disseminator, agenda setter and framing agent, and the ongoing efforts by many others to gain media coverage ${ }^{5}$ this accomplishment is no small feat.

The differences in tobacco themes contained in newspapers/ newswires compared with television stories, and by specific outlets, could be helpful in planning efforts. ${ }^{9}$ Tobacco prevention and control advocates, as well as researchers, may want to carefully consider what tobacco themes they choose to develop, or which media outlets to target, if they want to increase their chances of gaining news coverage, that is, television news producers may be more likely to be receptive to cessation stories. Conversely, advocates could use these findings to attempt to educate television news producers about the importance of covering more population-based tobacco stories.

Research suggests that the volume of news media stories on tobacco is associated with cigarette sales, cessation and youth smoking behaviour. ${ }^{4}$ The news media surveillance system can be used to help monitor the impact of public health campaigns to reduce tobacco use, such as efforts to let the public know about the availability of cessation services. Because paid antitobacco advertisements are expensive and difficult to sustain for long periods of time, however, the system's greater value lies in its ability to provide a practical and inexpensive way to help assess the effectiveness of earned media efforts.

These findings illustrate that long-term tracking of news media stories on tobacco is practical, useful and relatively inexpensive. It may serve as a model for other countries to consider as a way to monitor tobacco-related news coverage. In addition to news media sources, surveillance in the USA and some countries has been expanded to include monitoring of tobacco product prices and tobacco industry advertising and promotional expenditures.

From a research perspective, given the large number of tobacco television stories identified in the US system, more detailed and refined analyses of television transcripts are warranted. Finally, news media tracking data could be analysed in conjunction with information from other sources (eg, surveys) to examine the potential influence of news coverage of tobacco in relation to populationbased changes in attitudes, beliefs, behaviour, or policies.

\section{What this paper adds}

- News media coverage is critically important for tobacco prevention and control. With increased attention on other health issues, such as the growing problem of obesity, tobacco issues may be receiving less attention in the USA and other countries over time. Few systematic analyses of ongoing news media coverage of tobacco issues across many years have been conducted.

- This study, which used a public health surveillance model to examine US newspaper and television coverage of tobacco from 2004 to 2010, found that the number and type of tobacco stories in newspapers and on television have remained relatively constant over time. These findings suggest that media advocacy and other efforts to keep tobacco stories in the news appear to have been successful in recent years, but such efforts need to continue over time to support programs and maintain public awareness.
Contributors All the authors fulfil all 3 criteria for authorship on this manuscript.

Competing interests None.

Provenance and peer review Not commissioned; externally peer reviewed.

\section{REFERENCES}

1 Dearing J, Rogers E. Agenda Setting. Thousand Oaks, CA: Sage, 1996.

2 Chapman S, Lupton D. The fight for public health: principles and practice of media advocacy. London: BMJ Publishing Group, 1994.

3 Mackenzie R, Johnson N, Chapman S, et al. Smoking-related disease on Australian television news: inaccurate portrayals may contribute to public misconceptions. Austr N Zealand I Public Health 2009;32:144-6.

4 National Cancer Institute. The Role of the Media in Promoting and Reducing Tobacco Use. Tobacco Control Monograph No. 19. Bethesda, MD: U.S. Department of Health and Human Services, National Institutes of Health, National Cancer Institute. NIH Pub. No. 07-6242, 2008.

5 Wakefield MA, Brennan E, Durkin SJ, et al. Making news: the appearance of tobacco control organizations in newspaper coverage of tobacco control issues. Am $J$ Health Promotion 2012;26:166-71.

$6 \mathrm{Kim} \mathrm{S-H}$, Willis LA. Talking about obesity: news framing of who is responsible for causing and fixing the problem. J Health Comm 2007;12:359-76.

7 Wakefield MA, Brennan E, Durkin SJ, et al. Still a burning issue: trends in the volume, content and population reach of newspaper coverage about tobacco issues. Crit Public Health 2011;21:313-25.

8 Shatenstein S. If it bleeds, it leads: the pathos derby. Tobacco Control 2004;13:97-9.

9 Nelson DE, Evans WD, Pederson LL, et al. A national surveillance system for tracking tobacco news stories. Am J Prev Med 2007;32:79-85.

10 Durrant $\mathrm{R}$, Wakefield M, McLeod $\mathrm{K}$, et al. Tobacco in the news: an analysis of tobacco issues in Australia. Tob Control 2001;12(Suppl 2):S75-81.

11 Pew Research Center. The State of the News Media 2013: An Annual Report on American Journalism. Washington, DC: Pew Research Center, 2013. http:/l stateofthemedia.org/ (accessed 5 Apr 2013).

12 Stillman FA, Cronin KA, Evans WD, et al. Can media advocacy influence newspaper coverage of tobacco: measuring the effectiveness of the American stop smoking intervention study's (ASSIST) media advocacy strategies. Tob Control 2001;10:137-44

13 Smith KC, Wakefield M, Siebel C, et al. Coding the news: the development of a methodological framework for coding and analyzing newspaper coverage of tobacco issues. ImpacTeen Research Paper Series, No. 21. Chicago IL: University of Illinois at Chicago, 2002

14 Smith KC, Terry-McElrath Y, Wakefield M, et al. Media advocacy and newspaper coverage of tobacco issues: a comparative analysis of 1 year's print news in the United States and Australia. Nicotine Tob Res 2005;7:289-99.

15 Long M, Slater M, Lysengen L. US news media coverage of tobacco control issues. Tobacco Control 2006;15:367-72.

16 Caburnay CA, Kreuter MW, Luke DA, et al. The news on health behavior: coverage of diet, activity, and tobacco in local newspapers. Health Ed Behav 2003;6:709-22.

17 Clegg Smith K, Wakefield MA, Edsall E. The good news about smoking: How do U. S. newspapers cover tobacco issues? J Public Health Policy 2006;27:166-81.

18 Niederdeppe J, Farrelly MC, Wenter D. Media advocacy, tobacco control policy change and teen smoking in Florida. Tob Control 2007;16:47-52.

19 Kaiser Family Foundation \& Center for Media and Public Affairs. Assessing Local Television Coverage of Health Issues. Menlo Park, CA: Kaiser Family Foundation \& Center for Media and Public Affairs, 1998.

20 Gale E. Choosing the News: How Newspaper Editors Define Newsworthy and Decide on Front Page Stories. Saarbrucken, Germany: VDM Dr. Muller Verlag, 2009.

21 Read D. The Power of News: The History of Reuters. 2nd ed. New York: Oxford University Press, 1999.

22 lyengar S, Kinder DR. News that Matters: Television \& American Opinion. Updated edition. Chicago, IL: University of Chicago Press, 2010.

23 Audit Bureau of Circulations. The Top 25 U.S. newspapers. Arlington Heights, IL: Audit Bureau of Circulations, 2011.

24 Moynihan R, Bero L, Ross-Degnan D, et al. Coverage by the news media of the benefits and risks of medication. N Eng J Med 2000;342:1645-50. 